\title{
Encenando a diferença em palcos metropolitanos: as trajetórias de Sara Baartman e Franz Taibosh
}

Performing difference on metropolitan stages: the life courses of Sara Baartman and Franz Taibosh

Juliana Braz Dias e Geovanna Belizze

\section{(2) OpenEdition}

\section{Journals}

\section{Edição electrónica}

URL: http://journals.openedition.org/aa/6697

DOI: $10.4000 /$ aa. 6697

ISSN: 2357-738X

\section{Editora}

Programa de Pós-Graduação em Antropologia Social (UnB)

Edição impressa

Paginação: 304-324

ISSN: 0102-4302

\section{Refêrencia eletrónica}

Juliana Braz Dias e Geovanna Belizze, «Encenando a diferença em palcos metropolitanos: as trajetórias de Sara Baartman e Franz Taibosh», Anuário Antropológico [Online], v.45 n.3 | 2020, posto online no dia 16 setembro 2020, consultado o 27 abril 2021. URL: http://journals.openedition.org/aa/ 6697 ; DOI: https://doi.org/10.4000/aa.6697

\section{cc) (†) $\odot$}

Anuário Antropológico is licensed under a Creative Commons Atribuição-Uso Não-Comercial-Proibição de realização de Obras Derivadas 4.0 International. 


\section{Encenando a diferença em palcos metropolitanos: as trajetórias de Sara Baartman e Franz Taibosh}

Performing difference on metropolitan stages: the life courses of Sara Baartman and Franz Taibosh

DOI: https://doi.org/10.4000/aa.6697

Juliana Braz Dias • Universidade de Brasília - Brasil

ORCID: $\odot \odot \odot \odot-\odot \odot \odot 3-\odot 316-971 X$ juliana.dias@unb.br

Professora do Departamento de Antropologia da Universidade de Brasília (UnB). Pesquisadora associada no Departamento de Sociologia e Antropologia Social da Universidade de Stellenbosch (SU) e no Centro de Estudos Africanos da Universidade da Cidade do Cabo (UCT). Tem desenvolvido pesquisa sobre cultura popular em Cabo Verde e na África do Sul.

\section{Geovanna Belizze • Universidade de Brasília - Brasil}

Mestranda no Programa de Pós-Graduação em Antropologia Social da Universidade de Brasília (PPGAS/ UnB). Integra o Laboratório de Etnologia em Contextos Africanos (ECOA/DAN/UnB). Atualmente realiza pesquisa sobre a indústria da moda na Cidade do Cabo, África do Sul.

Este artigo examina os "espetáculos etnológicos" que exibiam pessoas de origem africana em palcos da Europa e dos Estados Unidos, com fins pseudoeducacionais ou para simples entretenimento. Privilegiando uma perspectiva comparativa, observamos as histórias de vida de Sara Baartman, nomeada "a Vênus Hotentote", e Franz Taibosh, conhecido pelo nome artístico "Clicko, o bosquímano selvagem dançarino". Suas trajetórias pessoais e suas performances nos palcos revelam processos estruturais de construção da alteridade que estão no coração dos projetos imperialistas. Argumentamos que essa noção de alteridade é composta por um conjunto amplo de marcadores sociais e hierarquias inter-relacionados.

Espetáculos etnológicos. Colonialismo. Sara Baartman. Franz Taibosh. Interseccionalidade.
This article considers the "ethnological shows" that exhibited people of African origin on stages in Europe and the United States, for pseudo-educational purposes or simple entertainment. Privileging a comparative perspective, we observe the life histories of Sara Baartman, named "the Hottentot Venus", and Franz Taibosh, known by the stage name "Clicko, the wild dancing bushman". Their personal stories and performances on stage reveal structural processes of alterity construction that are at the very heart of imperialist projects. We argue that this notion of alterity is composed of a broad set of interrelated social markers and hierarchies.

Ethnological shows. Colonialism. Sara Baartman. Franz Taibosh. Intersectionality. 
Um espetáculo pode ser examinado como uma instituição singular, com características que a particularizam. Entre elas, está a capacidade de reunir, em um mesmo tempo e espaço, o artista e o público. Mas tal aproximação se faz simultaneamente a um processo, explícito ou implícito, de segregação. Mecanismos diversos - como a iluminação e o palco - são usados para provocar a separação entre os espectadores e aqueles que realizam a performance (Beeman, 1993) ${ }^{1}$.

Neste artigo, observamos um tipo particular de espetáculo, com longa existência no mundo ocidental. Tratamos dos "espetáculos etnológicos" que levaram aos palcos da Europa e dos Estados Unidos indivíduos de origem africana, para exibições com fins pseudoeducacionais (baseadas no racismo científico de então) ou para simples entretenimento. A prática de exibir "exemplares" de povos estrangeiros acompanhou a história de expansão europeia pelo mundo. Em 1550, a cidade francesa de Rouen organizou um festival que incluía, entre suas atrações, a recriação de uma "aldeia brasileira", com a presença de 50 indígenas (Wintroub, 1998). Outros indígenas, dessa vez capturados na América do Norte, foram o centro da atenção de espectadores londrinos que, em 1603, assistiram ao espetáculo dos estrangeiros ameríndios que remavam numa canoa pelo rio Tâmisa (Vaughan, 2009). Já no século XIX e início do século XX, quando os europeus avançaram pelo interior do continente africano com ambições imperialistas, o interesse de empresários do show business voltou-se para o tráfico de corpos negros, novos personagens imersos no imaginário metropolitano.

Em comum entre esses vários espetáculos etnológicos está a tendência a aproximar fisicamente europeus e nativos de várias partes do mundo, colocando-os em um mesmo espaço, ao mesmo tempo em que constroem, por meio da performance, uma alteridade radical ${ }^{2}$. Indígenas das Américas, Ásia, África, Austrália e ilhas do Pacífico eram apresentados aos curiosos olhos europeus de modo a consolidar a crença na superioridade destes últimos. Nas palavras de Lindfors (1999, p. xii), "os africanos [e outros não europeus] eram colocados no palco a fim de distanciá-los do resto da humanidade”.

A análise aqui proposta parte da comparação entre as trajetórias de duas pessoas de origem africana transformadas em espetáculo: Sara Baartman, nomeada a "Vênus Hotentote", e Franz Taibosh, conhecido pelo nome artístico "Clicko, o bosquímano selvagem dançarino". Ambos nascidos no extremo sul do continente africano. Ela, em torno de 1770. Ele, por volta de 1870. Procuramos comparar duas histórias de vida que, apesar de separadas pelo intervalo de um século, carregam semelhanças estruturais que caracterizam o mundo colonial.

Nossa intenção é contribuir para as reflexões sobre os processos estruturais de construção do Outro que estão no coração dos projetos imperialistas. Procuramos discutir os variados modos de produção da diferença, que se desdobra em um conjunto amplo de marcadores sociais e hierarquias inter-relacionados. Examinamos, para tanto, as biografias de Sara Baartman e de Franz Taibosh. Suas trajetórias, sob um olhar comparativo, são capazes de revelar o entrelaçamento de gênero, sexualidade, raça, etnia, classe, idade e nacionalidade na construção de sistemas de poder.
1 Este trabalho contou com auxílio financeiro do $\mathrm{CNPq}$ (Bolsa de Produtividade em Pesquisa, Bolsa de Mestrado e Bolsa de Iniciação Científica), da FAP-DF (Programa de Bolsas de Pós-Doutorado no Exterior e Edital Demanda Espontânea) e do Decanato de Pesquisa e Inovação da Universidade de Brasília (DPI/UnB). Agradecemos também às pareceristas anônimas por seus comentários.

2 Não nos referimos aqui à discussão de Baudrillard e Guillaume (2008), para quem a alteridade radical é uma construção produtiva, capaz de desafiar o nosso pensamento e romper com o nosso narcisismo cultural. Falamos aqui da construção de um Outro lançado ao limiar da humanidade. É a alteridade tomada como um mistério impenetrável que não abala a percepção do Eu. 
A transformação de Franz Taibosh em "Clicko" nos é apresentada por Neil Parsons (2010). O trabalho de Parsons é a única obra de fôlego que se dedica a reunir em uma narrativa coesa registros deixados sobre Taibosh. Laurens van der Post publicou, em 1976, o livro A Mantis Carol, que aborda igualmente a vida de Taibosh. Trata-se, contudo, de uma obra tida como "muito romantizada", com várias informações incorretas (Van der Schyff, 2011, p. 151). Entendemos que essa crítica pode, em maior ou menor grau, ser aplicada a qualquer obra de caráter biográfico. Neil Parsons também reúne dados de pesquisa e especulações várias, compondo sua narrativa sobre a vida de outra pessoa. É assim que lemos as obras aqui tomadas como fonte: narrativas possíveis, produto do emaranhamento entre história e imaginação.

Já a "Vênus Hotentote" tem inspirado vasta produção. Numa lista que não se pretende completa, mas bastante abrangente, podemos citar: Gilman (1985), Gordon (1992), Fausto-Sterling (1995), Sharpley-Whiting (1999), Strother (1999), Abrahams (2000), Magubane (2001), Samain (2001), Badou (2002), Guy-Sheftall (2002), Hobson (2005), Holmes (2007), Samuelson (2007), Crais e Scully (2009), Willis (2010), Gordon-Chipembere (2011), Kerseboom (2011), Qureshi (2011), Ritter (2011) e Lyons (2018). O caráter icônico da vida de Sara Baartman, tomada como símbolo da exploração do corpo e da sexualidade da mulher negra, faz dela objeto de variadas reflexões, com diversos objetivos e perspectivas teóricas. Tem inspirado também a produção de peças teatrais, romances, instalações artísticas e filmes, a exemplo dos premiados The Life and Times of Sara Baartman: "The Hottentot Venus" (1998) e The Return of Sara Baartman (2003). O caso de Sara Baartman tem rendido muitas controvérsias historiográficas. Não seria a própria literatura acadêmica responsável por construir um mito em torno da Vênus Hotentote, transformada em símbolo do "corpo da mulher negra"? Uma perspectiva africanista seria mais eficiente para dar a Sara Bartman voz, agência e pessoalidade? As narrativas sobre Baartman falam mesmo sobre ela ou sobre as agendas do presente? Quem tem o direito de falar sobre Sara Baartman?

Nós, as autoras, partilhamos da inquietação diante da complexidade e fragilidade dessas mediações. Concordamos que são múltiplos os modos de contar uma estória, que narrativas servem propósitos e que frequentemente elas vêm acompanhadas de especulações buscando compensar as incertezas. Por outro lado, defendemos a necessidade de lançarmos um olhar antropológico sobre obras de caráter biográfico como um caminho que se soma ao das clássicas etnografias (Hughes, 2018).

É preciso ficar claro que não pretendemos contribuir com novos dados sobre a vida de Sara Baartman e de Franz Taibosh. A originalidade deste artigo está em acionar a comparação como um método que permite enriquecer a reflexão sobre suas vidas, levantando novos pontos para a análise. Sob a perspectiva comparativa, dados que anteriormente pareciam meros "detalhes" das biografias ganham relevância - tanto para uma melhor compreensão dessas trajetórias pessoais, quanto para uma reflexão mais ampla sobre os projetos imperialistas, seus mecanismos e seus impactos, não só nas colônias, mas também nas metrópoles. 


\section{Exibindo a diferença}

Os "espetáculos etnológicos" apresentavam uma fronteira tênue com relação aos "shows de horrores" (freak shows). A exibição comercial de humanos considerados aberrações da natureza tem longa tradição, com grande popularidade principalmente nos séculos XIX e XX. Diversos tipos de "anomalias" tornavam-se atração: gigantismo, nanismo, hirsutismo, gêmeos xifópagos e variadas alterações morfológicas congênitas. A exibição (em teatros, circos e feiras) de pessoas consideradas aberrações trazia satisfação ao público, correspondendo a curiosidades mórbidas e cimentando uma noção de normalidade supostamente compartilhada pelos espectadores.

Os espetáculos etnológicos, a princípio, contrastavam com os shows de horrores pelo interesse que direcionavam ao "típico" - não ao "anormal". Se as aberrações eram tomadas como características individuais desviantes e raras (derivando daí seu interesse), as pessoas exibidas nos espetáculos etnológicos eram identificadas como um tipo representativo de um povo estrangeiro, homogeneizado em sua estranheza (Strother, 1999, p. 25). Além disso, estes espetáculos pretendiam ser eventos educativos, alegadamente com base científica. Mas muitas das estratégias dos shows de horrores acabaram sendo adotadas também na divulgação comercial dos espetáculos etnológicos, borrando a fronteira entre os dois ${ }^{3}$.

Sara Baartman e Franz Taibosh eram, assim, apresentados como típicos hotentote e bosquímano, respectivamente ${ }^{4}$. Ao serem levados para a Europa (e Estados Unidos, no caso de Taibosh), foram absorvidos por um imaginário metropolitano já existente sobre esses dois povos. Ambos estavam destinados a alimentar ideias produzidas pelo colonialismo - sobretudo a noção de alteridade, que, atribuída aos colonizados, era fundamental para o sucesso do empreendimento colonial. Como afirmam Cooper e Stoler,

a tensão mais básica do império repousa no que se tornou um ponto central, agora óbvio, dos estudos coloniais recentes: a saber, que a alteridade das pessoas colonizadas não era inerente nem estável; sua diferença tinha que ser definida e mantida (Cooper; Stoler, 1997, p. 7; tradução das autoras).

À medida que o convívio se aprofundava nas colônias, as fronteiras entre colonizadores e colonizados se tornavam mais porosas. Os contatos e as trocas que tinham lugar nas sociedades coloniais davam origem a hibridismos, misturas e apropriações (Trajano Filho; Braz Dias, 2015, p. 11). E quanto mais frágeis essas fronteiras, maior a necessidade de investimento na fabricação e manutenção dessas categorias. Os africanos eram continuamente construídos como o "outro" a partir do qual os europeus construíam a si próprios e seus impérios. Concentremo-nos no caso dos nativos da África austral.

Antes do século XVI, a região ao sul da África havia se mantido relativamente isolada. Por conta das condições climáticas da região, seus habitantes limitavam-se a pequenos e dispersos grupos de caçadores-coletores. Entre esses povos havia notável diversidade linguística. Viviam em grupos de aproximadamente vinte a
3 Para uma análise abrangente dos eventos de exibição humana na Inglaterra do século XIX, ver: Qureshi (2011).

4 "Hotentote" e "bosquímano" eram termos correntes no período aqui abordado. Posteriormente, foi reconhecido o caráter pejorativo desses termos, que foram substituídos, em especial nos meios acadêmicos, por "khoikhoi" e "san" (ou "khoisan", para se referir ao conjunto desses povos). Mais recentemente, novos questionamentos e ressignificações têm ocorrido, inclusive com a retomada do termo "bosquímano" (agora de modo enaltecedor) por alguns ativistas no âmbito das políticas identitárias na África do Sul. 
oitenta indivíduos, ligados por parentesco ou laços de dependência (Thompson, 2001, p. 7).

$\mathrm{Na}$ Península do Cabo, onde o regime de chuvas era mais adequado, esses povos passaram a se dedicar também à criação de ovelhas e gado. Foram esses grupos pastoralistas e caçadores-coletores que os europeus encontraram quando começaram a se instalar no extremo sul da África. Os europeus vieram a chamar tais pastoralistas de hotentotes (khoikhoi), enquanto os caçadores-coletores foram denominados bosquímanos (san) ${ }^{5}$.

Durante séculos, os khoisan representaram no imaginário europeu o elo perdido entre os humanos e os primatas. A imagem hegemônica dos khoisan entre os europeus do século XIX era a de uma criatura escassamente humana, sem língua, sem religião, sem organizações políticas minimamente sofisticadas e quase sem capacidade de raciocínio (Strother, 1999, p. 13; Gargallo, 2015, p. 53). A questão linguística é especialmente relevante, uma vez que os cliques, comuns entre as línguas das populações khoisan, faziam com que os europeus não as reconhecessem como uma língua verdadeira. Isso empurrava os khoisan para a fronteira entre a humanidade e a bestialidade.

O imaginário europeu sobre os khoisan construía-se também em torno de uma verdadeira obsessão com a sexualidade desses povos. As mulheres khoisan eram associadas à esteatopigia e à hipertrofia dos pequenos lábios ${ }^{6}$. Havia também uma fixação na genitália masculina. Desde muito cedo, viajantes europeus em visita à Colônia do Cabo relatavam que homens khoikhoi tinham apenas um testículo. Era quase unanimidade a crença na existência de monorquidia entre os khoikhoi, muitas vezes descritos como semieunucos (Gordon, 1992, p. 188-189). Os homens khoikhoi, portanto, não eram vistos como sexualmente ameaçadores - ao contrário das mulheres khoikhoi, hipersexualizadas. Importa notar que esse discurso europeu, sustentado pela ciência de então, reforçava a ideia de que os "hotentotes" formavam uma espécie separada e inferior à "raça negra" (Strother, 1999, p. 39).

Somam-se a esse imaginário depreciativo as condições de vida dos khoisan ao longo do desenvolvimento da Colônia do Cabo. No século XVIII, já tinham perdido seus rebanhos e suas terras, transformados em mão de obra barata para fazendeiros brancos no sul da África. Ainda que fossem legalmente considerados homens livres, viviam sob um regime de servidão, sem salário monetário, muitas vezes pagos com tabaco ou bebidas alcoólicas de baixa qualidade. No extremo, chegaram a ser alvo de campanhas de extermínio (Strother, 1999; Thompson, 2001; Gargallo, 2015).

Os chamados hotentotes e bosquímanos foram assim atrelados a uma imagem de criaturas na fronteira da humanidade, que, por sua vez, justificava sua exploração. Em 1809, sob o governo colonial britânico, os khoikhoi assumiram o status jurídico de tutelados (Strother, 1999, p. 22). A alteridade dos khoisan era continuamente reforçada por discursos e práticas que alimentavam os contrastes (ficcionais) entre colonizados e colonizadores, legitimando, por fim, o colonialismo.

É preciso notar que essa fabricação de uma alteridade radical era um processo amplo, envolvendo simultaneamente as colônias e as metrópoles. A criação de um
5 Mesmo consideradas adequadas no meio acadêmico, ambas as categorias, khoikhoi e san, são produto do encontro colonial, não servindo como um retrato exato dos grupos, com fronteiras muito porosas, que habitaram por séculos a África austral pré-colonial (Gargallo, 2015, p. 52).

6 A esteatopigia (acúmulo excessivo de gordura nas nádegas) e a hipertrofia dos pequenos lábios são condições encontradas em algumas - não todas! - mulheres khoisan. Tais características também não se restringem a essas populações. Contudo, foram associadas estritamente às mulheres khoisan e tomadas como uma condição que enfatiza sua sexualidade, sem necessariamente fazer delas sexualmente atraentes - sexed but not sexy (Strother, 1999, p. 22). 
mercado de consumo e espetacularização do “outro" na Europa é apenas mais uma etapa desse processo. Quanto mais bem-sucedidos os espetáculos etnológicos, mais forte a retórica que justificava os impérios.

\section{Sara Baartman e a Vênus Hotentote}

O que se sabe de Sara Baartman e da Vênus Hotentote - a pessoa e o espetáculo - é o que disseram sobre ela ${ }^{7}$. Estima-se que tenha nascido na década de 1770 , na região que é hoje o Cabo Oriental, na África do Sul. Baartman era de um grupo khoikhoi, falante de gonaqua. No extremo sul da África, passaria a maior parte de sua vida - primeiro, em uma fazenda colonial na qual vivia em regime de servidão e onde aprendeu a língua holandesa; depois, a partir de 1795, na Cidade do Cabo, após ser adquirida para trabalhar na casa de um rico mercador.

É importante notar que a Cidade do Cabo de início do século XIX era uma cidade portuária, cosmopolita. Antes mesmo de chegar à Europa, portanto, Sara Baartman já vivia em um contexto urbano. Morou com ao menos duas outras famílias, sempre servindo no âmbito doméstico. Teve três filhos, embora todos tenham morrido ainda bebês. Um deles foi fruto de uma relação afetiva que Sara Baartman manteve por dois anos, em coabitação, com um soldado holandês, Hendrick van Jong. Há indícios de que, ainda no Cabo, Baartman teria começado a fazer apresentações cujo foco recaía sobre seu corpo (Crais; Scully, 2009, p. 50). Foi quando Hendrik Cesars (a quem Sara Baartman servia no momento) e Alexander Dunlop (um escocês tentando resolver sua vida financeira) viram nela a possibilidade de ganharem dinheiro, levando-a para a metrópole ${ }^{8}$.

Dunlop foi quem administrou a carreira de Sara Baartman na Inglaterra. Ao chegar em Londres, ela foi alocada no centro da cidade, em uma das regiões mais nobres e movimentadas da capital, a rua Piccadilly. Neste respeitável centro da indústria de entretenimento, Sara Baartman receberia milhares de visitantes dispostos a pagar para conhecê-la. O espetáculo de Baartman, pautado na exibição da diferença, poderia não ser considerado exótico o suficiente para o público londrino, num período em que, entre um milhão de habitantes, em torno de 10 mil eram (homens) negros (Crais; Scully, 2009, p. 67). Portanto, é a particularidade da narrativa construída sobre Sara Baartman que fez dela uma grande atração.

Sara Baartman não era apenas uma mulher negra. Ela era uma "hotentote", que, como vimos, representava, no discurso científico de então, a fronteira entre a humanidade e a animalidade, inferior inclusive a outros nativos africanos. Essa característica vinha destacada em seu nome artístico, Vênus Hotentote, que habilmente evidenciava também outros marcadores presentes em seu corpo. A referência à deusa grega colocava em relevo sua sexualidade. Acionava uma linguagem erótica, sem, contudo, fazer de Sara Baartman um ideal universal de beleza feminina. Aos olhos ocidentais que a consumiam, ela não deveria despertar desejo, e sim risos e horror (Strother, 1999, p. 22).

A exibição da Vênus Hotentote foi pautada pela narrativa sobre um corpo extraordinário. O empresário de Sara Baartman contratou um dos gravuristas mais famosos da Inglaterra para produzir o material de divulgação do espetáculo. Um
7 Duas supostas entrevistas com Sara Baartman apareceram em jornais parisienses em 1815. Estas são pouco acreditadas. Uma é uma sátira, que ao longo do texto zomba de Baartman, e a outra parece uma conversa fictícia, sobre um passado idealizado. Além disso, Baartman foi entrevistada em Londres, em 1810 , em um caso judicial. Mas o que se tem registrado é uma paráfrase da entrevista, que foi conduzida em um ambiente intimidador para Sara Baartman, que teria se limitado a respostas evasivas. Ver: Crais; Scully (2009, p. 128 e 99).

8 Hendrik Cesars era descendente de escravos oriundos do sudeste asiático. Nasceu na Colônia do Cabo na década de 1760, já com o status de homem livre. Alexander Dunlop, nascido na Escócia na década de 1750 , era um viajado cirurgião militar (Crais; Scully, 2009). 
pôster - que não reflete exatamente o modo como Baartman se apresentava informava ao público como deveriam vê-la: uma caricatura, radicalmente diferente dos espectadores (Fig. 1). O desenhista destacava a nudez, a esteatopigia, o cachimbo, as pinturas faciais, o kaross (manto de pele de animal) e um bastão, remetendo a uma vida nômade. Os fios pendentes na parte frontal do seu vestuário completavam o caráter sexual daquela figura, fazendo uma alusão ao que não podia ser exibido em público: a suposta hipertrofia dos pequenos lábios (Strother, 1990, p. 29)9.

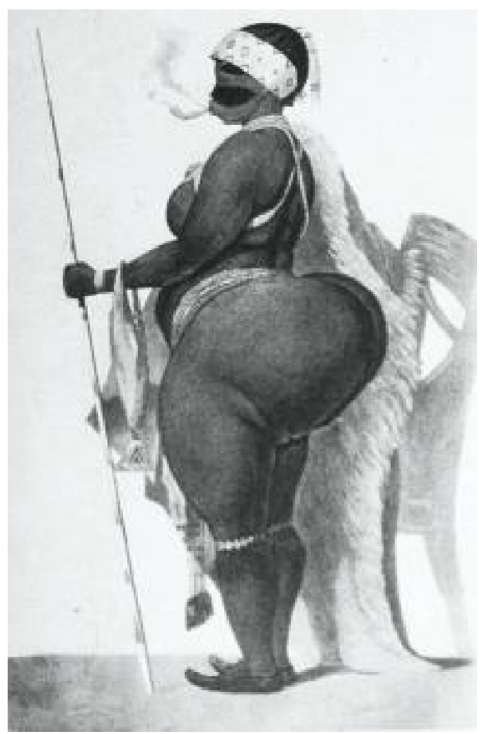

Figura 1 - "Sartjee, the Hottentot Venus". Fonte: Strother, 1999, p. 28.

O espetáculo de Sara Baartman, em si, era chocantemente simples. Não era um grande espetáculo como os shows de horrores circenses vieram a ser. Tampouco trazia uma narrativa explícita sobre sua vida e seu passado, o que contrastava com outras exibições de pessoas africanas feitas na Inglaterra naquele período. Nas exibições que aconteceram, tanto em Piccadilly como nas casas de nobres e ricos, Baartman usava um vestido marrom justo, que aludia à nudez. Quando instruída, virava-se de costas para que os visitantes pudessem observar suas nádegas e, sob um pagamento, até mesmo tocá-las. Homens e mulheres considerados respeitáveis na sociedade londrina compunham o público.

O espetáculo construído em torno de Sara Baartman tornou-se foco de um processo legal, movido por Zachary Macaulay (1768-1838) e outros membros de um grupo abolicionista que questionava as condições de exibição de Baartman. Naquele momento, a Inglaterra havia encerrado oficialmente sua participação no tráfico de escravos, mas a exploração colonial britânica ganhava cada vez mais força na África. O próprio Zachary Macaulay, líder abolicionista, estava envolvido em controvérsias referentes à manutenção de práticas escravagistas na Serra Leoa. Ao demonstrar que desejava resgatar uma "mulher africana" da condição de escravidão, buscava recuperar sua própria honra como "humanista beneficente"
9 O Museu Britânico, ainda hoje, detém os direitos de propriedade sobre algumas gravuras de Sara Baartman, cobrando para o uso das mesmas. Sua imagem, portanto, continua sendo monetizada. 
- ainda que ele mesmo nunca tenha dialogado diretamente com Sara Baartman (Crais; Scully, 2009, p. 83 e 89).

Depois desse questionamento legal - que não chegou de fato à condenação dos responsáveis por Sara Baartman - o espetáculo da Vênus Hotentote tomou novo rumo, evitando performances que pudessem ser julgadas, naquele contexto, como ofensivas. Se a princípio ganharam público devido à atenção que o caso teve, sem a alusão à nudez e a permissão do toque na nova versão do show, o público logo perdeu entusiasmo.

Durante a estadia de Baartman em Paris, para onde seguiu em 1814, o espetáculo da Vênus Hotentote tornou a ganhar grande atenção. Diversas reportagens apareceram em jornais, com charges que contrapunham a civilização europeia e o caráter primitivo de seu corpo. Havia diversos comentários sobre sua feiura nas páginas dos jornais, que colocavam as mulheres europeias como o verdadeiro ideal de beleza. A mulher hotentote era vista como antítese da beleza e da moral europeias (Gilman, 1985, p. 212).

Mas o que foi mais marcante na temporada de Sara Baartman em Paris foi sua apropriação pela ciência, que levou a uma exposição ainda maior do seu corpo. Georges Cuvier (1769-1832), aclamado cientista francês tido como "pai da paleontologia" e "pai da anatomia comparativa", demonstrou grande interesse por Sara Baartman. Ela foi algumas vezes examinada e desenhada por Cuvier e sua equipe. Esses cientistas não apenas tinham interesse em catalogar e descrever, mas buscavam formular uma teoria sobre a hierarquia das espécies. Acreditavam que quanto mais pronunciadas eram as genitálias, mais primitivo seria o mamífero. Diante dos rumores de que mulheres hotentotes possuíam os pequenos lábios alongados, examinar as genitálias de Baartman parecia uma oportunidade inigualável. Seria, para o grupo de cientistas, a prova da sexualidade incontrolável e do caráter animal dos hotentotes. Porém, enquanto viva, Sara Baartman negou acesso aos seus órgãos genitais (Crais; Scully, 2009, p. 134).

Após a morte de Sara Baartman, em 1815, devido a uma provável pneumonia, Cuvier obteve permissão para manter o corpo sob seu domínio. Ele confirmou a presença de genitais alongadas ao dissecá-la. Preservou seus órgãos e fez um molde de seu corpo que, até a década de 1970, era exibido no Museu do Homem em Paris. O corpo de Sara Baartman, portanto, continuou sendo exibido mesmo depois de sua morte. Estima-se que a exibição do molde de seu corpo na Exposição Internacional de 1937, em Paris, tenha atraído 31 milhões de pessoas (Crais; Scully, 2009, p. 2). E não terminou aí sua trajetória.

Em 1995, quando a África do Sul havia recém-eleito Nelson Mandela como presidente e o país vivia a transição para o período democrático, o retorno de Sara Baartman foi reivindicado por ativistas khoikhoi, com o argumento de que ela deveria ter um funeral digno. Seria também um processo de restauração da dignidade da nação sul-africana, após o período colonial. A negociação com a França durou sete anos. Apenas em 2002, durante o governo de Thabo Mbeki, os restos mortais de Sara Baartman retornaram à África do Sul. Em 9 de agosto de 2002, no Dia Nacional da Mulher, ela foi enterrada em Hankey (Cabo Oriental), seu provável local de nascimento. 
O silenciamento de Sara Baartman continuou permitindo que sua história fosse apropriada e ideologicamente distorcida, agora por outras narrativas. Baartman foi tomada como um símbolo do sofrimento impingido às mulheres negras - o que ficou evidente na escolha por realizar seu funeral no Dia Nacional da Mulher, data voltada para as ações contra a violência baseada no gênero.

Sara Baartman foi apropriada, sobretudo, no processo de construção da nação. Tornou-se uma importante ferramenta política na construção de uma nação mais inclusiva, reinventada no projeto de Rainbow Nation de Nelson Mandela. A “Nação Arco-Íris" era a representação de uma nova comunidade política a ser erguida por meio da coexistência pacífica entre muitas e diversas culturas que compõem a África do Sul. Baartman tornou-se um ícone nacional, simbolizando o passado aborígene como a "mãe" de todos os sul-africanos (Kerseboom, 2011). Se durante o colonialismo ela foi usada em um processo de construção da alteridade que justificava o império, no pós-colonialismo ela foi transformada em símbolo da identidade de um povo, legitimando a nação em formação.

Durante o governo de Thabo Mbeki, fundado na ideia de "Renascença Africana", Sara Baartman representaria também uma África descolonizada, investida de poder para fazer frente à ciência Ocidental (Kerseboom, 2011). Nesse sentido, destacamos ainda que, em 2018, a Universidade da Cidade do Cabo (UCT), em meio a um processo de descolonização da instituição, iniciado pelos estudantes, renomeou um de seus principais edifícios como Sarah Baartman Hall. O edifício levava antes o nome de Leander Starr Jameson, que atuou como primeiro ministro na Colônia do Cabo.

Importa notar também que Sara Baartman continuou representando a herança khoisan, especificamente. Se ela simboliza a união nacional sul-africana perante o mundo, internamente ela representa igualmente os pleitos dos indígenas khoikhoi e san, que continuam marginalizados no contexto atual, pós-apartheid. Ela é um símbolo para ativistas khoikhoi que hoje se reúnem para reivindicar, sobretudo, o direito à terra.

\section{Franz Taibosh e Clicko}

A história de Franz Taibosh não foi reproduzida, recontada e questionada na mesma escala que a de Sara Baartman. Seu caso aproxima-se mais de milhares de outros que fizeram parte da indústria de shows de horrores e tiveram seus nomes apagados da memória coletiva.

Estima-se que Franz Taibosh tenha nascido em Middelburg (no atual Cabo Oriental, África do Sul) por volta do fim dos anos 1860 ou início dos anos 1870, marcando assim um século do nascimento de Sara Baartman. Seu pai era khoikhoi e sua mãe, provavelmente, san - Taibosh era falante de korana, uma língua khoi, além do africâner (Parsons, 2010, p. xv). Na Colônia do Cabo, trabalhou em uma fazenda africânder. Enquanto seu pai e irmãos foram trabalhar na criação de animais, Taibosh foi escolhido para atuar no âmbito doméstico, fazendo faxina, comida e serviços de jardinagem. Atuou também como mensageiro durante a guerra Anglo-Boer (1899-1902). Acredita-se que, em algum momento, tenha trabalhado 
no entretenimento das tropas britânicas, como dançarino, mímico e comediante.

Franz Taibosh saiu da África do Sul acompanhado por Paddy Hepston (1877-?), que detinha sua custódia. Hepston era um irlandês judeu que falava africâner e já tinha algum envolvimento com o mundo do teatro. Franz Taibosh, conhecido também como $\mathrm{Clicko}^{10}$,passou um longo período nos palcos. Quando Paddy Hepston, atuando como empresário de Taibosh, leva-o para os palcos ingleses em 1913, o público era muito diferente daquele que foi ver as apresentações de Baartman. Apesar do contínuo interesse pelo "outro", os ingleses já estavam acostumados a ver homens negros (africanos e estadunidenses) realizando variados tipos de performance (Parsons, 2010, p. 36). A estratégia do empresário de Taibosh, a princípio, foi anunciar o espetáculo como Dancing Bushman, destacando não apenas sua origem (aliás, equivocadamente) como também seu talento como dançarino.

O espetáculo contava com uma narrativa fictícia introdutória - elemento comum aos shows de horrores. Hepston projetava um curto filme mudo (produzido ainda no continente africano), enquanto contava a estória de como ele, um fazendeiro na colônia, havia descoberto o bosquímano no mundo selvagem. A imagem da captura era especialmente destacada (Parsons, 2010, p. 40-41). O espetáculo tinha continuidade com a dança. Franz Taibosh, além de dançar, urrava, gritava em sua língua nativa e demonstrava alto nível de energia. O figurino escolhido para Taibosh nessa fase de sua exibição era apenas uma tanga. E, já nesse início, era anunciado como tendo "quase 100 anos de idade" (Parsons, 2010, p. 38). Destacava-se assim o corpo pequeno e enrugado de Taibosh. Somando-se ainda o tom de sua pele, marrom-claro, ele se encaixava perfeitamente no estereótipo do bosquímano.

Acadêmicos da Universidade de Cambridge interessaram-se pela curiosidade etnológica que era apresentada. Na universidade, recebeu elogios por sua dança e habilidade de imitar animais. W. L. H. Duckworth (1870-1956), especialista em anatomia vinculado ao Laboratório Antropológico de Cambridge, demonstrou grande interesse pelo caso. Concluiu, porém, que Taibosh não falava língua alguma - algo ainda recorrente na percepção europeia das línguas khoisan. Mas suas conclusões, bem como as estórias de Paddy Hepston, chegaram a ser divulgadas na África do Sul, onde especialistas, junto da mídia, rapidamente refutaram os "achados" e afirmaram que Duckworth tinha sido enganado.

O tempo de Taibosh e seu empresário na Inglaterra foi curto. Houve acusações referentes ao modo como Hepston tratava Taibosh, relatando que os maus tratos físicos chegavam a debilitá-lo. Um dos acadêmicos do grupo em Cambridge, Robert D. Vernon, escreveu para a APS (Aborigines' Protection Society) em 1913, denunciando o caso. Uma segunda testemunha escreveu para APS em 1914, que dessa vez abriu uma investigação. Hepston, porém, escapou, seguindo com Taibosh para a Irlanda, onde conseguiram sumir de vista da polícia local.

Restou ao empresário de Franz Taibosh recorrer aos shows de horrores do outro lado do oceano, mais precisamente em Cuba, considerada na época um centro de entretenimento dos norte-americanos. Foi em Cuba que o potencial da performance de Taibosh foi observado por um dos homens mais influentes do
10 O nome Clicko foi atribuído a Franz Taibosh devido à sua língua nativa, que inclui vários cliques entre os seus fonemas. 
campo do entretenimento nos Estados Unidos, Samuel W. Gumpertz (1868-1952). Em acordo com Hepston, Gumpertz assumiu a guarda de Taibosh e levou ambos para os Estados Unidos, para integrá-los nos shows de horrores que produzia. Taibosh continuaria a ser apresentado como um homem de idade extremamente avançada - vendiam a ideia de que ele tinha até 110 anos -, e pequena estatura, exageradamente apresentada como sendo de pouco mais de um metro, com 32 quilos. O destaque dado ao corpo pequeno e franzino, assim como ao rosto enrugado e à cor "acobreada", distanciava-o de um imaginário de virilidade do homem negro africano. Segundo Parsons (2010, p. 84), a imagem de Clicko era de alguém "mais fofinho do que feroz".

A vida de Franz Taibosh nos Estados Unidos não foi menos conturbada, pessoal e profissionalmente. Do lado profissional, foi objeto de disputa entre dois grandes nomes do entretenimento norte-americano: o já mencionado Gumpertz e Frank Cook (1873-1937), que representava o circo Barnum \& Bailey, um dos maiores e mais famosos da época. $O$ circo era tão grande que fazia suas estreias no Madison Square Garden, em Nova York, e cumpria longas turnês ao longo do ano pelo país.

No Barnum \& Bailey, Clicko fazia parte da procissão de aberrações. Hepston vestia uma calça cáqui e usava chapéu e um chicote - ainda encenando o colono - e Franz Taibosh aparecia vestido em uma túnica de pele de leopardo (Fig. 2). $\mathrm{O}$ vestuário era simples, limitando-se à túnica larga, que remetia a um mundo "selvagem" e tornava seu corpo ainda mais franzino. Às vezes dançava descalço, outra vezes com um par de botas, que destacava seus passos. O empresário ainda narrava a captura do bosquímano, enquanto Taibosh dançava e interagia com a plateia, gritando e rosnando, provocando sustos e risadas. Em 1922, chegaram a produzir um panfleto para acompanhar a performance, com maiores detalhes sobre a (fictícia) captura. Por outro lado, Franz Taibosh foi progressivamente aprimorando sua performance, encenando a passagem da "selvageria" à "fofura", dos movimentos ameaçadores aos gestos cômicos (Parsons, 2010, p. 98).

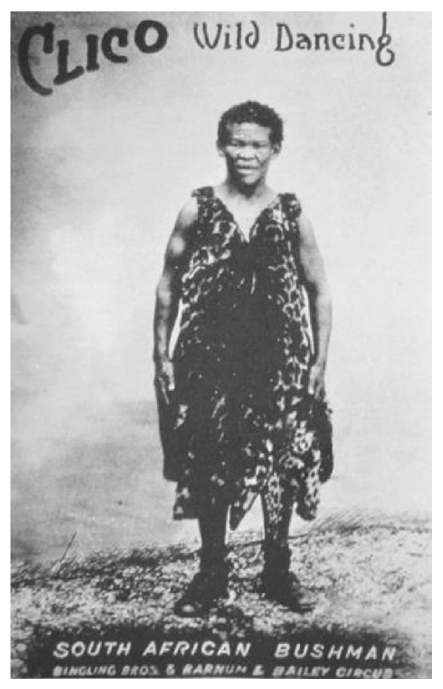

Figura 2 - Panfleto publicitário de Clico Wild Dancing Bushman.

Fonte: Parsons, 2010, p. 136. 
No circo, Taibosh ganhou respeito profissional. Tinha uma relação amistosa com o seleto grupo que integrava o desfile de aberrações - todos orgulhosamente identificados como artistas. Mas chegou a ser levado por Cook para ser examinado por especialistas do Museu Americano de História Natural, onde foi feito seu molde, de corpo inteiro. Uma série de fotografias também foi feita para o Museu, intitulada "Bosquímano Africano" - incluindo fotografias de seu corpo nu (Parsons, 2010, p. 91).

Em sua vida fora dos palcos, o seu tratamento não parecia melhor do que aquele que gerou denúncias na Inglaterra. Hepston continuava tratando-o como seu serviçal e submetendo-o a maus tratos. Isso levou a um episódio definidor na vida de Taibosh, que é narrado por diferentes vozes (excluindo a do próprio Taibosh, silenciado pelas fontes). Parsons (2010, p. 105-109) informa que, em 1918, Taibosh foi visitado por um dos funcionários do circo (aproveitando a ausência de Hepston), o qual teria se espantado com as condições em que vivia, mal alimentado e seminu. Ao tomar conhecimento, Frank Cook, o representante legal do circo Barnum \& Bailey, sentindo-se "moralmente responsável”, teria "sequestrado" Taibosh, levando-o para a casa de sua própria filha, que cuidou da saúde do pequeno homem. A polícia local também tratou o caso, inicialmente, como um sequestro. O jornal The Bridgeport Post relata que Taibosh teria "implorado" para ser levado dali, gesticulando para comunicar que vinha sendo alimentado apenas com água e pão velho. Relata também que Taibosh teria sido encontrado usando "meias de mulher, roupa íntima de mulher, sapato de mulher". Em outra narrativa, a família de Cook conta que Taibosh foi levado "de modo amigável". O cônsul britânico em Nova York, por sua vez, escreveu a seus superiores dizendo que Taibosh havia "desertado", buscando a "proteção" de Cook.

Cook cuidou dos arranjos legais para a permanência de Franz Taibosh nos Estados Unidos, sob sua responsabilidade. Nesse período, ao se desvincular de seu antigo empresário, Taibosh passou a dominar a língua inglesa, comunicando-se com mais facilidade. No verão, seguia em turnê com o circo Barnum \& Bailey; no inverno, hospedava-se na casa da filha de Cook. Junto com a família Cook, frequentava espaços de elite (festas, teatros e jantares), situações nas quais ele procurava entreter os presentes, com seus modos divertidos. Cook e Taibosh pareciam bem próximos, sempre bebendo e se divertindo juntos. Frequentavam lugares como campo de golfe, resort de ski e bordéis. Cook era seu "guardião" legal. O salário que Taibosh recebia como artista de circo era controlado por Cook.

Quando Frank Cook faleceu, sua família continuou vivendo com Taibosh. Em 1939, Franz Taibosh foi diagnosticado com uma doença de coração que já se manifestava há algum tempo, dificultando seu trabalho no circo. Em seus últimos dias de vida, Taibosh ficou na casa da filha de Cook e seu marido (Frances e Patrick Sullivan). Taibosh morreu em 31 de agosto de 1940, sendo enterrado em Hudson, Nova York. Sua morte foi registrada na seção de óbitos do The New York Times.

Algumas descrições do temperamento de Taibosh foram registradas. O jornal londrino Daily Chronicle o descreveu como "muito galante" com as mulheres, "mandando beijos, colocando sua mão no coração e fazendo o Don Juan com 
perfeição" (apud Parsons, 2010, p. 51). Muitos mencionam os excessos de Taibosh no consumo de bebidas alcoólicas. Mencionam também seu lado sempre divertido. Mas é a família de Cook que fornece a maior parte dos relatos sobre Taibosh. Frances, a filha mais velha, conta que Cook deu a Taibosh a opção de voltar para a África do Sul e que ele preferiu ficar nos Estados Unidos. Ela disse que Taibosh era "completamente americanizado". Disse que ele estava satisfeito e orgulhoso de sua posição. E que quando perguntavam sua origem, Taibosh dizia: "Eu sou um cavalheiro norte-americano" (Parsons, 2010, p. 133). Nessas narrativas, o bosquímano ganha (informalmente) nacionalidade norte-americana, contrastando com Sara Baartman, que é hoje identificada em várias narrativas como sul-africana (mesmo sabendo que a África do Sul, enquanto nação, não existia ainda no tempo de Baartman).

\section{Duas vidas em contraste}

Em Couro Imperial, Anne McClintock examina o imperialismo britânico, evidenciando como esse projeto político global está absolutamente entrelaçado à ordem econômica capitalista branca e à ordem reprodutiva da monogamia patriarcal, revelada no culto à domesticidade (McClintock, 2010, p. 18-19). Para a autora, o imperialismo não pode ser plenamente compreendido sem uma reflexão conjunta sobre gênero, raça e classe. Ela argumenta que essas três categorias, conforme elaboradas na modernidade industrial, não existem em isolamento. Elas existem "em relação entre si e através dessa relação" (McClintock, 2010, p. 19), reforçando a importância de uma perspectiva interseccional.

Quando insistimos, acima, que a noção de alteridade foi forjada pelo empreendimento colonial como forma de garantir sua própria existência, abrimos espaço para pensar essa alteridade sendo construída por múltiplos caminhos. A primeira grande invenção necessária para a legitimidade dos impérios foi a distinção entre as categorias de colonizador e colonizado (Cooper; Stoler, 1997). Mas essa distinção, base do empreendimento colonial, desdobrava-se em outras, relacionadas de forma sistêmica. Estão incluídos aqui os processos de diferenciação e hierarquização de gênero, de sexualidade, de classe e de raça -temas trabalhados habilmente por McClintock -, mas ainda outros, que procuramos evidenciar neste artigo. Argumentamos, a partir de um olhar comparativo sobre as trajetórias de Sara Baartman e Franz Taibosh, que a discussão sobre interseccionalidade pode ser ampliada incluindo outros marcadores sociais, como etnia, idade e nacionalidade. Essas outras categorias não são menos importantes ou menos decisivas. Elas afetam umas às outras e compõem, junto às demais formas de diferenciação, um mesmo projeto de poder.

A extensa literatura produzida sobre Sara Baartman evidencia como as dimensões do gênero e da raça foram definidoras em sua trajetória. Não apenas afetaram as experiências vividas por Baartman, mas também as narrativas póstumas que a tornaram um ícone da mulher negra. Lançamos aqui outras questões, complementares, nascidas da comparação entre a sua biografia e a de Franz Taibosh. Não teria a etnia sido tão ou mais importante para a compreensão da história de 
Sara Baartman quanto a noção de raça? ${ }^{11}$ Como se deu, na vida de Baartman e Taibosh, a relação entre sexualidade e domesticidade? Como ambos viveram a passagem do tempo? Qual o espaço de agência por eles encontrado na vida pessoal e profissional?

Vimos como a identificação de Sara Baartman como uma mulher hotentote/ khoikhoi foi fundamental para o olhar construído sobre ela no século XIX. Embora as narrativas póstumas (acadêmicas ou não) revelem uma tendência a apresentá-la como uma "mulher negra" ou uma "mulher africana", o interesse que ela despertou na ciência de então estava justamente relacionado ao fato de não ser ela exatamente como as outras mulheres africanas. Georges Cuvier e sua equipe viram em Baartman a peça que faltava no que pretendiam ser uma teoria científica da hierarquia das espécies. No âmbito do racismo científico do século XIX, Baartman não era vista como as demais mulheres negras, uma vez que (supostamente) apresentava genitálias mais pronunciadas, o que acreditavam ser uma característica das espécies mais primitivas. Sara Baartman seria inferior às demais mulheres africanas. Ela estaria no limiar entre a humanidade e a animalidade, justamente pela sua identificação como mulher hotentote/khoikhoi - um dado frequentemente ausente das análises sobre Sara Baartman.

Um século depois, com Franz Taibosh, mesmo após modificações significativas na noção científica de raça, sua origem khoisan ainda despertava o interesse da ciência ocidental, de modo particular. Foi como "bosquímano" que atraiu a atenção de Duckworth, na Universidade de Cambridge - o qual retomou inclusive o mito de que os bosquímanos não falavam língua alguma. Mas os novos tempos mostravam uma modificação também nas colônias, que passaram a ser, elas próprias, produtoras de conhecimento científico. Especialistas ao sul da África foram incisivos na crítica aos "achados" de Duckworth. A antropóloga e filóloga Dorothea Bleek (1873-1948), em especial, evidenciou vários erros nas conclusões do cientista britânico ${ }^{12}$.

A identificação de Baartman e Taibosh como hotentote e bosquímano, respectivamente, teve desdobramentos muito distintos nas imagens construídas sobre a sexualidade dos dois. A etnia ganhou novos contornos quando atrelada à diferença de gênero. A exploração da sexualidade de Sara Baartman, como vimos, visava sustentar uma teoria sobre o corpo primitivo. A esteatopigia e a hipertrofia dos pequenos lábios eram tomadas, por um lado, como uma característica comum às mulheres hotentotes/khoikhoi e, por outro lado, como a prova de uma sexualidade feminina excessiva e predatória. $O$ corpo da Vênus Hotentote era tão central para o público que, no momento em que a vestem mais, o interesse por sua performance começa a desvanecer.

Ao observarmos o caso de Taibosh, percebemos uma narrativa muito distinta sobre sua sexualidade. Karlien van der Schyff (2011) afirma que:

Os diferentes estereótipos aos quais estiveram sujeitos Baartman e Taibosh [...] formam a diferença mais crucial entre suas apresentações; a diferença entre seus respectivos shows não é, portanto, necessariamente dependente
11 Estamos cientes de que o termo "etnia" carrega aqui alguma anacronia. Certamente, não é uma categoria usada nos períodos históricos vividos por Sara Baartman e Franz Taibosh (assim como "gênero" também não o é). Usamos o termo aqui como um conceito, uma categoria analítica.

12 Dorothea Bleek vinha de uma família de estudiosos sobre os khoisan. Seu pai, Wilhelm Bleek, e sua tia, Lucy Lloyd, foram pioneiros nos estudos sobre as línguas e culturas khoisan. 
dos diferentes períodos históricos nos quais eles foram exibidos, mas, sim, repousa no importante fato de que o corpo de Taibosh nunca foi moldado pelo tropo da hipersexualidade, como foi o de Baartman (Van der Schyff, 2011, p. 156; tradução das autoras).

Argumentamos que o caso de Clicko é mais ambíguo do que sugere Van der Schyff, demandando mais reflexão. Muitas vezes Franz Taibosh apresentou-se com poucas roupas. Também ele teve seu corpo nu transformado em um molde, que virou parte do acervo do Museu Americano de História Natural em Nova York. Seu corpo, portanto, também foi explorado, mas não da mesma maneira que o de Sara Baartman. Quando lembramos dos discursos construídos pelos europeus sobre os homens khoisan, desde o início da Colônia do Cabo, vemos que também ali era recorrente a menção às genitálias e, particularmente, à monorquidia como característica própria dos khoikhoi. Portanto, a sexualidade desses indígenas também foi sempre um objeto de atenção, mas, ao contrário das mulheres, hipersexualizadas, os homens khoikhoi eram vistos como menos viris, hipossexualizados. $\mathrm{E}$ essa imagem de alguma maneira é reproduzida nos discursos sobre Taibosh. Suas idas a bordéis, assim como suas brincadeiras "galanteadoras" com as mulheres, estão bem presentes nas narrativas contadas sobre ele. Mas, de modo ambivalente, Taibosh também era visto como alguém amigável e dócil, fofo e não ameaçador.

A ideia de um homem pouco viril era reforçada pela imagem de Taibosh como um homem pequeno, velho, enrugado e franzino. Aqui as construções sobre gênero, etnia e sexualidade relacionam-se também à idade. Seus (supostos) 100 anos de idade reforçavam seu exotismo no mercado dos shows de horrores, ao mesmo tempo que indicavam sua fragilidade e caráter não ameaçador. Sara Baartman, por sua vez, não tinha a idade identificada. Como veremos adiante, parecia congelada no tempo.

Tais imagens tinham reflexo direto também na noção de domesticidade. McClintock (2010, p. 20) apresenta o culto da domesticidade e a reinvenção ocidental do patriarcado como uma dimensão crucial das identidades de gênero, indispensável ao mercado industrial e à empresa imperial. A autora argumenta que é necessário observar o espaço doméstico para compreender plenamente como homens e mulheres, negros e brancos, experimentaram diferentemente o imperialismo. Partindo dessa ideia, propomos direcionar o olhar para alguns pontos das biografias de Baartman e Taibosh que passaram quase despercebidos pela historiografia sobre o tema.

Poucos foram os autores e autoras que se dedicaram a investigar a vida de Sara Baartman anterior à sua experiência na Europa. O trabalho de Crais e Scully (2009) destaca-se justamente por buscar mais informações sobre a vida de Baartman na Colônia do Cabo. Na obra, porém, tais dados não levam aos desdobramentos analíticos que procuramos indicar neste artigo.

A vida de Sara Baartman no Cabo esteve fortemente atrelada ao meio doméstico. No regime de servidão e tutela a que estavam submetidos os indígenas khoisan, Baartman foi sempre destinada ao serviço doméstico. A domesticação era 
a forma de dominação e de desvalorização do trabalho feminino na colônia. Na Cidade do Cabo, Sara Baartman experimentou a maternidade. Teve também um companheiro, com quem dividiu o lar, ainda que por pouco tempo. Mas todo esse histórico desaparece na imagem construída sobre ela no âmbito dos espetáculos apresentados ao público europeu.

A Vênus Hotentote era uma mulher arrancada da domesticidade. A maternidade e a dedicação ao serviço doméstico não tinham lugar na narrativa da mulher hipersexualizada, incontrolável e ameaçadora. A personagem apresentada no palco era uma mulher nômade, sem lar e ociosa, passando o tempo a fumar seu cachimbo. Essa imagem não apenas contribuía para a construção de um estereótipo da mulher hotentote primitiva, como também servia como um alerta didático para as mulheres da metrópole. A Vênus Hotentote lembrava o valor da domesticidade às mulheres "civilizadas", brancas e da elite que assistiam a seus espetáculos. Era uma espécie de policiamento que deixava subentendidos os riscos de outras "classes perigosas", mais próximas, como as prostitutas e as feministas ${ }^{13}$.

Apenas quando Sara Baartman é incorporada a narrativas pós-coloniais, durante o processo de construção da nação sul-africana, que ela volta a ser integrada ao âmbito doméstico. A maternidade ganha protagonismo na nova narrativa. Não se trata, contudo, da mulher que gerou três filhos e dedicou a maior parte de sua vida aos cuidados domésticos. O foco aqui, mais uma vez, é a Sara Baartman enquanto um símbolo: a mãe de toda uma nação.

Quando voltamos o olhar para Franz Taibosh, novamente se evidencia seu lugar ambíguo numa estrutura de poder que conjuga hierarquias de raça, etnia, gênero, sexualidade, classe e idade. Tal ambiguidade já começa a se revelar quando o jovem Taibosh, trabalhando numa fazenda africâner, "é escolhido" para realizar os serviços domésticos, contrastando com as atividades de outros homens khoikhoi. Trata-se, certamente, de uma informação pouco clara, mas que nos leva à reflexão. Estaria a virilidade de Taibosh sendo questionada ainda nas primeiras fases de sua vida?

Na Europa e nos Estados Unidos, Taibosh foi progressivamente construindo uma vida profissional fora do âmbito doméstico. Contudo, passou longo período desempenhando duplo papel: como artista de circo em turnê pelos Estados Unidos, durante o verão; recolhido na casa da família Cook (possivelmente trabalhando em atividades domésticas), durante o inverno.

Ainda outro ponto das narrativas sobre Taibosh merece atenção. Uma das descrições sobre seu "sequestro" inclui, entre os maus tratos a que era submetido pelo seu empresário, o frio, a fome e o uso de roupas e acessórios femininos. Não cabe aqui julgar a veracidade da narrativa, mas indicar mais esse elemento simbólico, o travestismo. A imagem de um homem vestido de mulher na intimidade de sua vida doméstica põe novamente em xeque sua virilidade. Mantém, portanto, ambígua (ou mesmo liminar) a posição de Taibosh em um sistema de dominação construído pela conjugação de diferentes marcadores sociais.
13 Ver, a esse respeito, McClintock (2010, p. 20), que inclui ainda nessa categoria de "classes perigosas" do mundo imperial: trabalhadores insurgentes, irlandeses, judeus, gays, lésbicas, criminosos e loucos, entre outros. 


\section{A mágica dos palcos}

Passamos, por fim, a uma análise direcionada especialmente para as performances da Vênus Hotentote e de Clicko, o Bosquímano Selvagem Dançarino. Nos palcos, Sara Baartman e Franz Taibosh construíram (ou foram levados a construir) dois personagens que alimentaram os projetos imperiais - da Inglaterra vitoriana no século XIX e, mais tardiamente, dos Estados Unidos como um império sem colônias.

A performance do Bosquímano Selvagem manteve, ao longo do tempo, alguns elementos essenciais, enquanto outros foram sendo progressivamente transformados. Entre os elementos fixos, destaca-se a narrativa que introduz o espetáculo. O filme exibido e a estória contada por Hepston servem como um enquadramento inicial do que está por vir. Ainda que não seja um recurso muito original no conjunto dos espetáculos etnológicos, merece um exame cuidadoso. Hepston, um judeu irlandês que falava africâner, estava longe de ser um representante legítimo do homem branco, civilizado, capitalista, colonizador. Ele estava mais próximo, simbolicamente, do público de trabalhadores que assistia ao show. Mas no contexto do espetáculo, diante de Clicko, a diferença se coloca de modo evidente, lançando o bosquímano para o limiar da humanidade. A narrativa segue com elementos de violência, destacando a "captura" do indígena - um ato carregado de sentido, que se coloca entre a violência e a salvação, ao tirá-lo da vida selvagem. Não por acaso, a vida de Taibosh é depois marcada por outra "captura". Os relatos sobre o "sequestro" de Taibosh por Cook são versões de uma mesma estrutura narrativa. Cook, representando o capitalista branco, atua na fronteira entre o crime e a benevolência, retirando o pequeno bosquímano (frágil, faminto, feminizado) das mãos de Hepston, agora realocado como o cruel e pouco civilizado judeu irlandês.

Por mais violenta que seja a narrativa da "captura" no espetáculo do Bosquímano Selvagem, ela é capaz de inserir Clicko numa historicidade. O bosquímano tem um passado "conhecido" (ao menos na ficção). E o destaque dado à sua idade (os supostos 100 anos) reforça a passagem do tempo, vivida pelo pequeno homem. Como um ritual, o espetáculo cria uma temporalidade particular, atrelada a uma espacialidade própria. A performance de Clicko nos circos estadunidenses se dá por meio de um desfile ou "procissão", junto aos demais artistas no show de aberrações. O espaço é percorrido pelo bosquímano, que nunca está parado.

Além disso, Taibosh parece ter incluído uma outra dinâmica em sua performance. Ele interpreta uma transformação que vai do selvagem (evidenciado no seu nome e no seu vestuário, bem como nos gritos ferozes) ao dançarino bem-humorado e cômico que diverte a plateia. Se essa interpretação de Parsons procede, vemos em Taibosh um artista que consegue imprimir a sua marca no espetáculo, originalmente concebido e enquadrado pela narrativa colonial de seu empresário. Apesar de viver claramente num contexto de exploração e dominação, além de ser silenciado pelas inúmeras narrativas sobre sua vida, percebemos a agência de Taibosh, que encontra brechas para se fazer ouvir.

Já o show da Vênus Hotentote, em sua simplicidade, remete a outra construção do tempo e do espaço. Baartman não é vista como uma artista no palco, encenan- 
do um espetáculo. Ela é apresentada como uma mulher congelada no tempo, sem uma história de vida, sem um passado. Ela é a própria representação do passado. Aproximamo-nos aqui da profícua crítica que Johannes Fabian (2014) faz da antropologia e seus usos do tempo. $\mathrm{O}$ autor argumenta que os antropólogos tendem a colocar o "outro", seu objeto de estudo, em uma temporalidade distinta. A separação no espaço se desdobra em uma separação no tempo. Os sujeitos estudados pelos antropólogos existiriam, assim, numa temporalidade não contemporânea a do próprio investigador. E, ao remeter o "outro" ao passado, a antropologia contribuiria para solidificar uma relação de poder. A crítica de Fabian atravessa as fronteiras da antropologia e pode ser estendida ao próprio projeto imperial. A construção da alteridade nas narrativas imperiais incluía entre os seus mecanismos o afastamento temporal. E é assim que vemos Sara Baartman no palco. A Vênus Hotentote é uma personagem alocada em uma temporalidade distinta da de seu público, congelada em um passado longínquo, primitivo, ameaçador.

O enquadramento espacial da performance da Vênus Hotentote segue a mesma narrativa. A mulher ali exposta aos olhares de outros quase não se movimenta pelo palco. Com a exceção de breves momentos em que se desloca seguindo os comandos (violentos) do apresentador, a Vênus mantém-se estática. Não apenas Baartman e Taibosh vivem em dois tempos e dois espaços distintos, mas as performances da Vênus Hotentote e de Clicko também constroem dois tempos e dois espaços contrastantes.

\section{Considerações finais}

Os shows de horrores e os espetáculos etnológicos conformam apenas um dos palcos montados pelo colonialismo. Esses shows foram vistos por milhões de pessoas que tiveram acesso a indivíduos como Sara Baartman e Franz Taibosh e suas performances, enquadradas pela retórica imperialista. Baartman, Taibosh e tantos outros encontraram pouco ou nenhum espaço para deixar registradas suas vozes e foram fadados a ter suas vidas contadas sob um imaginário construído na experiência colonial e alimentado pelos espetáculos dos quais eram parte.

Quando Victor Turner (1986) abordou a diferença entre o ritual e o teatro, indicou que os rituais buscam resultados e têm um público que participa e acredita na performance executada, uma vez que é esta uma criação da coletividade. Por outro lado, o teatro buscaria apenas a diversão de um público que assiste à performance sem se envolver e que faz uma apreciação crítica daquilo que é apresentado como produto da criatividade individual. Em suma, os dois gêneros representariam a oposição entre a eficácia e o entretenimento (Beeman, 1993, p. 379).

A análise aqui feita sobre os espetáculos etnográficos mostra, porém, que se o entretenimento não se perdia de vista, a eficácia também era buscada. Tais espetáculos eram pensados com o objetivo de divertir um público em momentos de lazer. Mas eles apresentavam também uma força criadora. As performances executadas por pessoas como Sara Baartman e Franz Taibosh eram absolutamente eficazes em cimentar a crença numa alteridade radical, compartilhada por muitos sob a lógica do império, tanto nas colônias quanto nas metrópoles. 
Juliana Braz Dias e Geovanna Belizze

Os espetáculos etnográficos e os shows de horrores contribuíram para a criação e a manutenção de um sistema global de dominação, que se sustentou no entrelaçamento de diferenciações e hierarquias de gênero, sexualidade, raça, classe e ainda outros marcadores, aqui abordados, como etnia, idade e (mais recentemente) nacionalidade.

Recebido: 05/06/2020

Aprovado: $17 / 08 / 2020$ 


\section{Referências}

ABRAHAMS, Yvette. Colonialism, dysfunction and disjuncture: the historiography of Sarah Bartmann. Tese (Doutorado em História) - University of Cape Town, Cidade do Cabo, 2000

BADOU, Gérard. L'enigme de la Vénus Hottentote. Paris: Payot, 2002.

BAUDRILLARD, Jean; GUILLAUME, Marc. Radical alterity. Cambridge: The MIT Press, 2008.

BEEMAN, William O. The anthropology of theater and spectacle. Annual Review of Anthropology, n. 22, p. 369-393, 1993.

COOPER, Frederick; STOLER, Ann Laura (Eds.). Tensions of empire: colonial cultures in a bourgeois world. Berkeley; Los Angeles; London: University of California Press, 1997.

CRAIS, Clifton; SCULLY, Pamela. Sara Baartman and the Hottentot Venus: a ghost story and a biography. Princeton; Johannesburg: Princeton University Press; Wits University Press, 2009.

FABIAN, Johannes. Time and the Other: how anthropology makes its object. Nova York: Columbia University Press, 2014.

FAUSTO-STERLING, Anne. Gender, race, and nation: the comparative anatomy of Hottentot women in Europe, 1815-1817. In: TERRY, Jennifer; URLA, Jacqueline (Eds.). Deviant bodies: critical perspectives of difference in science and popular culture. Bloomington: Indiana University Press, 1995. p. 19-48.

GARGALLO, Eduard. De las visiones coloniales a las políticas postcoloniales: el caso de los San de Namibia. Anuário Antropológico, v. 40, n. 2, p. 51-76, 2015.

GILMAN, Sander L. Black bodies, white bodies: toward an iconography of female sexuality in late nineteenth-century art, medicine and Literature. Critical Inquiry, v. 12, n. 1, p. 204-242, 1985.

GORDON, Robert J. The venal Hottentot Venus and the Great Chain of being. African Studies, v. 51, n. 2, p. 185-201, 1992.

GORDON-CHIPEMBERE, Natasha (Ed.). Representation and black womanhood: the legacy of Sarah Baartman. Nova York: Palgrave Macmillan US, 2011.

GUY-SHEFTALL, Beverly. The body politic: black female sexuality and the nineteenth-century Euro-American imagination. In: WALLACE-SANDERS, Kimberly (Ed.). Skin deep, spirit strong: the black female body in American culture. Ann Arbor: University of Michigan Press, 2002. p. 13-35.

HOBSON, Janell. Venus in the dark: blackness and beauty in popular culture. New York: Routledge, 2005.

HOLMES, Rachel. African Queen: the real life of the Hottentot Venus. Nova York: Random House, 2007.

HUGHES, Heather. African biography and historiography. In: SPEAR, Thomas (Ed.). The Oxford Research Encyclopedia, African History. Nova York: Oxford University Press. 2018. Disponível em: https://oxfordre.com/africanhistory/view/10.1093/acrefore/9780190277734.001.0001/acrefore-9780190277734-e-229. Acesso em: 5 abr. 2020.

KERSEBOOM, Simone. Grandmother-martyr-heroine: placing Sara Baartman in South African post-apartheid foundational mythology. Historia, v. 56, n. 1, p. 63-76, 2011.

LINDFORS, Bernth. Introduction. In: Africans on stage: studies in ethnological show business. Bloomington: Indiana University Press, 1999. p. vii-xiii. 
Juliana Braz Dias e Geovanna Belizze

LYONS, Andrew. The two lives of Sara Baartman: gender, "race", politics and the historiography of mis/representation. Anthropologica, v. 60, n. 1, p. 337-346, 2018.

MAGUBANE, Zine. Which bodies matter? Feminism, poststructuralism, race, and the curious theoretical odyssey of the "Hottentot Venus". Gender and Society, v. 15, n. 6 , p. 816-834, 2001.

MCCLINTOCK, Anne. Couro imperial: raça, gênero e sexualidade no embate colonial. Campinas: Editora da Unicamp, 2010.

PARSONS, Neil. Clicko: the wild dancing bushman. Chicago: The University of Chicago Press, 2010.

QURESHI, Sadiah. Peoples on parade: exhibitions, empire, and anthropology in nineteenth-century Britain. Chicago: The University of Chicago Press, 2011.

RITTER, Sabine. Facetten der Sarah Baartman: Repräsentationen und Rekonstruktionen der “Hottentottenvenus". Münster: Lit Verlag, 2011.

SAMAIN, Étienne. Quando a fotografia (já) fazia os antropólogos sonharem: o jornal La Lumière (1851-1860). Revista de Antropologia, v. 44, n. 2, p. 89-126, 2001.

SAMUELSON, Meg. Remembering the nation, dismembering women?: stories of the South African transition. Pietermaritzburg: University of Kwazulu-Natal Press, 2007.

SHARPLEY-WHITING, T. Denean. Black Venus: sexualized savages, primal fears, and primitive narratives in French. Durham: Duke University Press, 1999.

STROTHER, Z. S. Display of the body Hottentot. In: LINDFORS, Bernth (Ed.). Africans on stage: studies in ethnological show business. Bloomington: Indiana University Press, 1999. p. 1-61.

THE LIFE and Times of Sara Baartman: "The Hottentot Venus”. Direção de Zola Maseko. Nova York: First Run; Icarus Films. Color, 53 min. 1998.

THE RETURN of Sara Baartman. Direção de Zola Maseko. Nova York: First Run; Icarus Films. Color, 55 min. 2003.

THOMPSON, Leonard. A history of South Africa. 3. ed. New Haven; London: Yale University Press, 2001.

TRAJANO FILHO, Wilson; BRAZ DIAS, Juliana. O colonialismo em África e seus legados: classificação e poder no ordenamento da vida social. Anuário Antropológico, v. 40, n. 2, p. 9-22, 2015.

TURNER, Victor. From ritual to theatre and back. Nova York: Performing Arts Journal, 1986.

VAN DER SCHYFF, Karlien. Staging the Body of the (M)other: the "Hottentot Venus" and the "Wild Dancing Bushman". In: GORDON-CHIPEMBERE, Natasha (Ed.).Representation and black womanhood: the legacy of Sarah Baartman. Nova York: Palgrave Macmillan, 2011. p. 147-163.

VAUGHAN, Alden T. Transatlantic encounters: American Indians in Britain, 1500-1776. Cambridge: Cambridge University Press, 2009.

WILLIS, Deborah. Black Venus 2010: they called her "Hottentot”. Philadelphia: Temple University Press, 2010.

WINTROUB, Michael. Civilizing the savage and making a king: The Royal Entry Festival of Henri II (Rouen, 1550). The Sixteenth Century Journal, v. 29, n. 2, p. 465-494, 1998. 